\title{
Lifetime study of sputtered PtAl coating on $\gamma$-TiAl with and without TBC topcoat at high temperatures
}

\author{
Authors: A. Ebach-Stahl ${ }^{1}$, M. Fröhlich ${ }^{2}$ \\ ${ }^{1}$ DLR - German Aerospace Center, Institute of Materials Research, 51170 Cologne, Germany \\ ${ }^{2}$ University of Applied Sciences, 08056 Zwickau, Germany \\ $\underline{\text { Contact Information: }}$ \\ Corresponding author: Andrea Ebach-Stahl \\ DLR - German Aerospace Center \\ Institute of Materials Research \\ 51170 Cologne, Germany \\ Email: andrea.ebach@dlr.de \\ Phone: +49 (0) 22036012557 \\ Maik Fröhlich: \\ University of Applied Sciences Zwickau \\ Faculty Physical Engineering / Informatics \\ Leupold Institute of Applied Sciences \\ Kornmarkt 1 \\ 08056 Zwickau, Germany \\ Email: maik.froehlich@fh-zwickau.de \\ Phone: +49 (0) 375 / 5361508
}




\begin{abstract}
In this study, a PtAl based coating was tested under high temperature conditions at $900^{\circ} \mathrm{C}$ and $1000^{\circ} \mathrm{C}$. The composition of Pt-53Al was chosen because of its excellent results in previous studies at another temperature. Due to the formation of a thin continuous alumina layer on top and the phase stability of the oxidation resistant coating, a lifetime of 1500 1h-cycles was achieved.

Depending on the testing temperature and time, the coating underwent an evolution of different Ti-Pt-Al phases due to the outward diffusion of $\mathrm{Ti}$ and $\mathrm{Nb}$ from the substrate and inward diffusion of Pt. The oxidation resistance decreases with a continued interdiffusion and a decreasing Pt content in the Ti-Pt-Al phases.

Additionally, the Pt-53Al coating was successfully deposited with a Thermal Barrier Coating top coat by EB-PVD. The oxidation test at $1000^{\circ} \mathrm{C}$ also revealed a lifetime up to 1500 cycles without failure, particularly based on the good adhesion between the TGO and TBC. Mass gain measurements were done at each temperature and for all coating systems. Further microstructural examination methods to study the coating evolution, such as scanning electron microscopy (SEM), energy-dispersive X-ray spectroscopy (EDS) and X-ray diffractometry (XRD) for phase analysis, were used.
\end{abstract}

Keywords: PtAl; $\gamma$-TiAl; oxidation; coating; magnetron sputtering, 7YSZ 


\section{Introduction}

Materials with a good oxidation and corrosion behavior are of high interest within the aerospace and automotive industry. State of the art Ni-based superalloys are used for components of aero and automotive engines as well as for gas turbines, which also provide attractive mechanical properties. Alumina former coating systems, such as $\mathrm{MCrAlY}(\mathrm{M}=\mathrm{Ni}$ and/or Co) [1-3] or Pt-modified aluminides [4-6], improve the oxidation resistance of the material.

However, mass reduction is one of the major goals for aeroengines. Light weight Titanium Aluminides, with their low density about $4 \mathrm{~g} / \mathrm{cm}^{3}$, are a material with attractive mechanical properties in a temperature range of $700-850^{\circ} \mathrm{C}[7,8]$. A sufficient creep resistance can be provided up to $750^{\circ} \mathrm{C}$ [9], but above $750^{\circ} \mathrm{C}$, a poor oxidation resistance characterizes this material due to the formation of fast growing and porous titania [10-12]. Therefore, an oxidation resistant coating is necessary to prevent material reduction by a fast oxidation process. Coatings based on the halogen effect [13-16] or sputtered coatings based on TiAl, TiAlCrZr/Y [16-21], as well as Si based coatings [22-24] show a positive effect on the oxidation behavior.

As shown in prior investigations, sputtered PtAl based coatings on $\gamma$-TiAl also provide an excellent oxidation resistance [25-28]. A thin and continuous $\mathrm{Al}_{2} \mathrm{O}_{3}$ layer was formed on top with a stable $(\mathrm{Ti}, \mathrm{Nb}) \mathrm{PtAl}_{2}$ layer below. In this paper, further results of the oxidation resistance of sputtered PtAl-coatings on TiAl are presented. The lifetime and microstructure of the best coating composition of previous works, Pt-53Al [25], was tested at further temperatures, namely $900^{\circ} \mathrm{C}$ and $1000^{\circ} \mathrm{C}$.

Additionally, the PtAl oxidation resistant coating was combined with a Thermal Barrier Coating (TBC) of yttria partially stabilized zirconia (7YSZ) on top within this study. Currently $7 \mathrm{wt} . \%$ yttria partially stabilized zirconia is the industrial standard for TBCs on Nibased superalloys. TBCs are widely used in aero-engines as well as land based gas turbines 
due to their low thermal conductivity. A temperature reduction up to $150^{\circ} \mathrm{C}$ can be achieved for components with internal cooling [29-31]. Due to the application of ceramic top coats, the material beneath will be protected by operating at lower temperatures $[32,33]$. Bondcoats with a good oxidation behavior, such as $\mathrm{Al}_{2} \mathrm{O}_{3}$ formation, provides good bonding between the TBC and substrate.

In this paper the coating system of a sputtered PtAl bondcoat with and without EB-PVD TBC consisted of $7 \mathrm{YSZ}$ was tested at testing temperatures of 900 and $1000^{\circ} \mathrm{C}$. 


\section{Experimental}

The $\gamma$-TiAl material (TNB V2) was provided by GfE (Germany) with the composition of Ti45Al-8Nb-0,8C. Disc shaped specimens were machined with the dimensions of $15 \mathrm{~mm} \mathrm{x}$ $1 \mathrm{~mm}$. Before the coating procedure, the specimens were mechanical pretreated by the following steps: Grinding with $\mathrm{SiC}$ paper, polishing with a $\mathrm{SiO}_{2}$ suspension and cleaning with ethanol.

The Pt-53Al coating was deposited by magnetron sputtering by using a two source equipment with the same process settings of previous experiments written in [25]. To get a homogeneous coating composition and thickness, the specimens were rotated in the coating chamber. The PtAl coating thicknesses were about $10 \mu \mathrm{m}$. Afterwards, a cyclic test was performed at $900^{\circ} \mathrm{C}$ and $1000^{\circ} \mathrm{C}$ in air. One cycle consists of $60 \mathrm{~min}$ heating time and $10 \mathrm{~min}$ cooling down to $60^{\circ} \mathrm{C}$. After 1500 cycles, the test was stopped. To study the microstructure evolution one sample was removed after 10,100, 500, 1000 and 1500 cycles. The high test temperature of $1000^{\circ} \mathrm{C}$ was chosen to find the capability concerning the oxidation resistance.

Six Pt-53Al coated specimens were used to investigate the adhesion of a ceramic top coat. The thermal barrier coating (TBC) used within this study consisted of yttria partially stabilized zirconia (7YSZ). Before the TBC coating process via electron beam physical vapor deposition (EB-PVD), it is necessary to pre-oxidize the PtAl coatings to provide good adhesion. Therefore, the samples were oxidized at $950^{\circ} \mathrm{C}$ for $10 \mathrm{~h}$ in air after magnetron sputtering. During the EB-PVD coating process, the samples were fixed on a planetary gear and the rotational speed was $4 \mathrm{rpm}$. The sample temperature was approximately $950^{\circ} \mathrm{C}$. The TBC-thickness was about $150 \mu \mathrm{m}$. The samples with a TBC top coat were also tested cyclically at $1000^{\circ} \mathrm{C}$ up to 1500 cycles. Similar to the samples without a TBC top coat, one sample was removed after the aforementioned cycle states to investigate the microstructure. During the oxidation tests, the mass gain of each sample was recorded. The microstructure was examined for all samples by standard metallographic preparation of cross sections 
followed by investigations at scanning electron microscopy (SEM; Zeiss Ultra 55) with energy-dispersive X-ray spectroscopy (EDS). Acceleration voltages of $3 \mathrm{keV}$ were used for image acquisitions and $20 \mathrm{keV}$ for EDS-analyses. For phase analysis, XRD measurements for selected samples were carried out using a Siemens D5000 powder diffractometer in BraggBrentano configuration with $\mathrm{Cu} \mathrm{K} \alpha$ radiation. 


\section{Results and discussion}

\subsection{Oxidation test at $900^{\circ} \mathrm{C}$}

The good oxidation behavior of the $\mathrm{Pt}-53 \mathrm{Al}$ coating at $950^{\circ} \mathrm{C}$ of previous investigations [25]was also verified at $900^{\circ} \mathrm{C}$. The samples were tested up to 1500 cycles and the coating showed no signs of failure. In figure 1, the mass gain over exposure time is shown. The mass gain after 1500 cycles is very low (less than $0,5 \mathrm{mg} / \mathrm{cm}^{2}$ ). Other comparable alumina forming coatings on TiAl, for example Ti-Al-Cr-Y, show a higher mass gain of about $1 \mathrm{mg} / \mathrm{cm}^{2}$ at $900^{\circ} \mathrm{C}$ after 1000 cycles [34].

During the thermal cyclic test, the PtAl coating underwent several phase transformations. All investigated TiPtAl-based phases $\left(\tau_{2}, \tau_{3}\right.$ and $\left.\tau_{4}\right)$ are also described in $[35,36]$ and confirmed with XRD-measurements (figure 2). The chemical composition of the phases measured by EDS-analysis (seen in table 1) correlates to the data of the ternary Ti-Pt-Al phase diagram (figure 3, [35]).

Microstructure investigations show that within the first 10 cycles, a dense thin alumina layer with a thickness of about 300nm formed on top (figure 4a). Simultaneously the amorphous and homogeneous dense sputter coating crystallized. Beneath the thermally grown oxide (TGO) a huge area of PtAl and a two layer interface of one phase with the composition of $\mathrm{TiPt}_{2} \mathrm{Al}$ and the $\tau_{4}$-TiPtAl phase were formed due to interdiffusion with the substrate. The mentioned $\mathrm{TiPt}_{2} \mathrm{Al}$-phase was only seen in the 10 cycle state. This phase could not be identified by XRD-measurements, however the peaks exist in the 10 cycles-diffractogram, which could not be collated to any other phases and disappeared after 100 cycles (figure 2). Maybe the peaks could have originated from this $\mathrm{TiPt}_{2} \mathrm{Al}$ phase.

After 100 cycles the interdiffusion continued, so that the PtAl layer gets thinner underneath the TGO and a $\mathrm{Pt}_{2} \mathrm{Al}_{3}$ layer formed between the PtAl layer and the $\tau_{4}$-layer (figure $4 \mathrm{~b}$ ). Although a relative high amount of $\mathrm{Ti}(11$ at.\%) and $\mathrm{Nb}$ (3 at.\%) exists in this phase, the XRD-diffractogram clearly shows reflexes of $\mathrm{Pt}_{2} \mathrm{Al}_{3}$ (figure 2). 
After 1500 cycles at $900^{\circ} \mathrm{C}$, the TGO consisted of pure $\mathrm{Al}_{2} \mathrm{O}_{3}$ and only had a thickness of about $1-1.5 \mu \mathrm{m}$. The PtAl-Bondcoat still existed with a thickness up to $20 \mu \mathrm{m}$ and consists of a layered structure of the $\tau_{2}, \tau_{3}$ and $\tau_{4}$ phases. In figure $4 \mathrm{c}$, the $\tau_{2}$ phase is visible with the dark grey contrast and the $\tau_{4}$ phase with the light grey contrast due to the higher amount of platinum. The $\tau_{3}$ phase is not optical visible, but this phase has to exist in the $\tau_{2}$-zones because EDS as well as XRD measurements show the existence of the $\tau_{3}$ phase.

In the initial states of $900^{\circ} \mathrm{C}$ oxidation test the $\mathrm{PtAl}$ and $\mathrm{Pt}_{2} \mathrm{Al}_{3}$ phases and the later formed $\tau_{2}$, $\tau_{3}$ and $\tau_{4}$ phases seem to be alumina formers. The solved Ti content in the $\mathrm{PtAl}$ and $\mathrm{Pt}_{2} \mathrm{Al}_{3}$ phases is relatively low in comparison to the other Pt-Al-based phases, so no oxidation of Ti took place. Presumably, the titanium in $\tau_{2}, \tau_{3}$ and $\tau_{4}$ is bonded strongly enough, so no oxidation of titanium was seen until 1500 cycles. The exclusive alumina formation results in a very low oxidation rate.

Additionally the outward diffusion of $\mathrm{Nb}$ coming from the substrate was observed. Apparently, the $\tau$-phases have a relatively high stability against diffusion and does not solute a high amount of $\mathrm{Nb}$, because the $\mathrm{Nb}$-content did not exceed over 8 at.\% after 1500 cycles at $900^{\circ} \mathrm{C}$. TiAlNb-precipitates of a relative high $\mathrm{Nb}$-content of about 20 at. $\%$ formed underneath the bondcoat, which confirm the conclusion of a relative low diffusion/solution of $\mathrm{Nb}$ in the PtAl-based phases.

\subsection{Oxidation test at $1000^{\circ} \mathrm{C}$}

Even at high temperature of $1000^{\circ} \mathrm{C}$ the $\mathrm{PtAl}$ coating shows an excellent oxidation behavior. Unfortunately, it was not possible to record oxidation kinetics. Due to the given sample geometry (seen in figure 1), the mass gain curve of the PtAl coating system decreased after about 300 cycles. This mass loss is caused by a high oxidation rate and oxide spallation at the region where there is a hole in the samples that was not or insufficient coated for the massive oxidation attack at this high temperature of $1000^{\circ} \mathrm{C}$. This hole, with a diameter of $1 \mathrm{~mm}$, is 
necessary to fix the specimens during both coating processes and cyclic testing. Hence the substrate is locally not protected enough and oxidized rapidly at $1000^{\circ} \mathrm{C}$. Although the oxidation kinetics of the $1000^{\circ} \mathrm{C}$ tests could not be continuously determined, it has been noted that the oxidation rate is very slow until spallation started after 300 cycles. In literature it is reported that mass gains for TiAlCrY based coatings on TiAl is about $1.2 \mathrm{mg} / \mathrm{cm}^{2}$ after 300 cycles without $\mathrm{TBC}$ at testing temperatures of $1000^{\circ} \mathrm{C}$ [34]. Thereby the mass gain of the PtAl coatings (about $0.6 \mathrm{mg} / \mathrm{cm}^{2}$ ) is approximately half of the value of TiAlCrY coatings and also lower in comparison of halogen treated TiAl material $\left(0.8-1.1 \mathrm{mg} / \mathrm{cm}^{2}\right)[37]$. At $1000^{\circ} \mathrm{C}$ the coating behavior is comparable to the 900 and $950^{\circ} \mathrm{C}$ test [25]. Due to the depletion of $\mathrm{Pt}$ by inward diffusion, a layer of $\mathrm{PtAl}$ precipitates was formed in a $\mathrm{Pt}_{2} \mathrm{Al}_{3}$ matrix in the upper part of the coating after 10 cycles (figure 5a). A double layer of $\tau_{3}$ and $\tau_{4}$, developed by interdiffusion, was formed underneath $\mathrm{Pt}_{2} \mathrm{Al}_{3}$. After 100 cycles, due to further interdiffusion, the PtAl isles are solved and only the $\mathrm{Pt}_{2} \mathrm{Al}_{3}, \tau_{2}$ and $\tau_{3}$ were observed. Similar to the $900^{\circ} \mathrm{C}$ investigations, all mentioned phases were confirmed by XRD measurements as seen in figure 6 and the compositions are listed in table 2.

During the $1000^{\circ} \mathrm{C}$-test, similar phase transformations occurred as in the $900^{\circ} \mathrm{C}$ test, so that after 1500 cycles, only the $\tau_{2}+\tau_{3}$ phases exists underneath the TGO (figure $5 b$ ). In summary, within in the $1000^{\circ} \mathrm{C}$ test, the same phase transformations could be seen in comparison to lower testing temperatures with the difference being that the transformation rate was faster due to the higher temperature and therefore faster interdiffusion.

However, during the test $\mathrm{TiO}_{2}$ also formed within the $\mathrm{TGO}$ at $1000^{\circ} \mathrm{C}$. The formation of titania with the rutile modification started locally after 1000 cycles. With longer exposure time more interdiffusion took place. So that the TiPtAl-based phases destabilized and the oxidation of the fast growing titania was possible. Due to the fast oxidation of titanium and aluminum after phase destabilization, Pt precipitates stayed inside the thick oxide areas (figure $5 \mathrm{~b}$ and XRD-diffractogram figure 6). Due to the small dimension of these precipitates, 
it could not be confidently determined if these precipitates were pure Pt or a kind of solid solution.

The effects of faster interdiffusion and phase transformation also can be seen in the XRDdiffractogram (figure 2+6). $\mathrm{PtAl}$ - and $\mathrm{TiPt}_{2} \mathrm{Al}$ formed during the first cycles at $900^{\circ} \mathrm{C}$ were not seen in the $1000^{\circ} \mathrm{C}$-diffractogram. Also the $\mathrm{Pt}_{2} \mathrm{Al}_{3}, \tau_{3}$ and $\tau_{4}$ phases, which were seen after 100 cycles at $900^{\circ} \mathrm{C}$, already were measured after 10 cycles during the $1000^{\circ} \mathrm{C}$ test. Additionally the XRD-investigations showed $\mathrm{TiO}_{2}+\mathrm{Pt}$ peaks at samples tested at $1000^{\circ} \mathrm{C}$ after 1000 cycles.

The microstructural examinations revealed that the formation of local blistering already started occurring after 500cycles. In figure 5c, a micrograph of a blister is represented that formed after 1000 cycles. It seems that oxygen passed through various channels, for instance small cracks, and reacted with titanium of the previously mentioned destabilized TiPtAlphases inside of the bondcoat. The fast growing titania needs more space and pushed the residual outer bondcoat outside and a blister was formed. Unfortunately parts of the formed titania broke out during cross section preparation, as seen in figure $5 \mathrm{c}$.

Astonishingly, the blister formation did not have an essential negative effect on the lifetime. But although the Pt-53Al coating reached at least 1500 cycles of $1000^{\circ} \mathrm{C}$ without spallation of the coating or TGO, it can be seen that the closed protective alumina layer exists no longer. The oxidation resistance of the coating reached the technical limit concerning the oxidation resistance at this temperature due to the formation of fast growing titania. The most of the oxidation resistant Pt-53Al-coating was depleted due to diffusion and rapid oxidation.

By comparison of all investigation steps at every testing temperature in this study and the former investigations at $950^{\circ} \mathrm{C}$ [25], the following evolution of TiPtAl-phases can be conclude, starting from the amorphous PtAl coating after sputtering process. This evolution is verified by XRD-measurements (Figure $2+6$ ): 
$\mathrm{PtAl}$ (amorphous) $\rightarrow \mathrm{PtAl}$ (crystalline) $\rightarrow \mathrm{TiPt}_{2} \mathrm{Al} \rightarrow \mathrm{Pt}_{2} \mathrm{Al}_{3} \rightarrow \tau_{4} \rightarrow \tau_{3} \rightarrow \tau_{2}$

First from the amorphous sputter coating, a crystalline PtAl bondcoat formed. In figure $4 \mathrm{a}+$ 5a, the PtAl and alumina phases can be seen after 10 cycles. Additionally, the $\mathrm{Pt}_{2} \mathrm{Al}_{3}$ phase formed at higher temperatures $\left(950^{\circ} \mathrm{C}[25]\right.$ and $\left.1000^{\circ} \mathrm{C}\right)$ in the first cycles, presumably, due to the rapid Pt depletion of the faster Pt inward diffusion (figure $5 \mathrm{a}+6$ ).

Due to further interdiffusion ( $\mathrm{Pt}$ inward diffusion and $\mathrm{Ti} / \mathrm{Nb}$ outward diffusion), the next transformations steps are the formation of $\tau_{4}, \tau_{3}$ and finally $\tau_{2}$ before the fast oxidation of titanium started. In general the transformation rate depends on the temperature beside time and, therefore on the diffusion velocity.

\subsection{Oxidation test at $1000^{\circ} \mathrm{C}$ with $\mathrm{TBC}$}

One major aim of this investigation was to elaborate whether a combination of a PtAl oxidation resistant coating with a thermal barrier top coat (TBC) of 7YSZ is feasible or not and if and how the TBC effects the oxidation behavior of the whole system.

Before applying the TBC by EB-PVD it was necessary to form a thin oxide scale to provide good adhesion of the ceramic top coat. Therefore, the samples were pre-oxidized for 10 hours at $950^{\circ} \mathrm{C}$ in air as noted in the "experimental" chapter.

Just as in the experiment without a $\mathrm{TBC}$ at $1000^{\circ} \mathrm{C}$, the recording of oxidation kinetics was also difficult. Due to the weak point around the hole, fast oxidation took place with subsequent spallation of small TBC and oxide pieces after 250 cycles in this area. However, the general surface of the sample did not show any failure. The samples with TBC reached a lifetime of at least 1500 cycles which was the point where the test was stopped.

First microstructure investigations were performed directly after deposition of the TBC (figure 7a). Due to the pre-oxidation before top coat manufacturing, the samples phase 
formation is similar to the 10 cycle state of the PtAl-coated samples without TBC. Beneath the TGO, $\mathrm{Al}_{2} \mathrm{O}_{3}$, a layered structure of PtAl, $\mathrm{Pt}_{2} \mathrm{Al}_{3}$ and $\tau_{4}$-TiPtAl formed. All element concentrations of the TiPtAl-based phases are listed in table 2.

The EB-PVD TBC was deposited with the typical columnar structure. Due to the smooth sample surface, the TBC grew up equally with a good adhesion to the pre-oxidized TGO $\left(\mathrm{Al}_{2} \mathrm{O}_{3}\right)$.

After 1500 cycles at $1000^{\circ} \mathrm{C}$, the PtAl coating was not completely oxidized, see figure $7 \mathrm{~b}$. Indeed a thick TGO of alumina and titania containing Pt-precipitates was formed, which remained after the oxidation of $\mathrm{Al}$ and Ti. Also the formation of pores was seen in the TGO. However, a thin dense alumina layer was seen beneath the TBC. This presence ensured a good adhesion of the TBC. Contrary to expectations no $\tau_{2}$-phase was seen, but a $\tau_{4}$-TiPtAl layer of about $5-10 \mu \mathrm{m}$ in thickness exists still after 1500 cycles between TGO and substrate. This behaviour has not yet been clarified.

Due to the thickness of the TBC, no XRD measurements were done. All mentioned TiPtAl phases are based on the experience of the other XRD measurements without TBC and EDS investigations.

Additionally, it is to be seen that the TGO expands in the interspaces of the TBC due to the outward diffusion of titanium (figure $7 \mathrm{~b}$ ). This behavior of forming an inner and outer oxide scale is also reported in literature [38, 39], but the influence of this oxidation behavior is still not fully explained.

The blistering, which was seen after the $1000^{\circ} \mathrm{C}$ test at samples without $\mathrm{TBC}$, could not be observed for samples with TBC topcoat. Areas of titania formation inside the intermetallic bondcoat were seen, but the TBC prevents the outward mechanical deformation of the coating. Feasible build internal stresses have no visible effect on the oxidation behavior and lifetime. 


\section{Summary}

The oxidation resistance of a Pt-53Al-coating on $\gamma$-TiAl was investigated after cyclic testing at $900^{\circ} \mathrm{C}$ and $1000^{\circ} \mathrm{C}$ in air. Although the chosen testing temperatures were quite high for a $\gamma$ TiAl alloy, the present investigations prove the applicability of the coatings up to this technical limit. A lifetime of at least1500 1h-cycles was observed. The formed alumina layer works as a barrier against the inward diffusion of oxygen and especially against the outward diffusion of titanium. This results in an excellent protection of the TiAl based material. During the thermal treatment, the amorphous Pt-53Al layer underwent several phase transformations according to the following scheme:

$\mathrm{PtAl}$ (amorphous) $\rightarrow \mathrm{PtAl}$ (crystalline) $\rightarrow \mathrm{TiPtAl}_{2} \rightarrow \mathrm{Pt}_{2} \mathrm{Al}_{3} \rightarrow \tau_{4} \rightarrow \tau_{3} \rightarrow \tau_{2}$

The transformations are depending on the exposure temperature and time and, therewith, on the diffusion rate of the elements involved.

The formation of titania with a rutile modification started locally after 1000 cycles at $1000^{\circ} \mathrm{C}$. Presumably, the continuously decreasing Pt-content due to the Pt inward diffusion, leads to a destabilization of the TiPtAl based phases and are a reason for this unwanted oxidation behavior. In addition, blister formation was observed after 500 cycles caused by fast titanium oxidation inside the bondcoat.

Additionally, a Thermal Barrier Coating of 7YSZ was deposited on the PtAl bondcoat and tested at $1000^{\circ} \mathrm{C}$ successfully. The results, especially the phase formation and evolution during the test, are comparable to these without $\mathrm{TBC}$ at $1000^{\circ} \mathrm{C}$. The $\mathrm{TBC}$ was still adhered after 1500 1h cycles without notable spallation, indicating an excellent adhesion and compatibility with this bond coat and the formed TGO. 


\section{Acknowledgment}

We thank J. Brien, C. Kröder and D. Peters (German Aerospace Center, Institute of Materials Research) for the technical support and coating manufacturing. The authors acknowledge gratefully Prof. Dr. Uwe Schulz for the discussions and comments regarding this work. 


\section{References}

1. Pint, B.A., et al., Substrate and bond coat compositions: factors affecting alumina scale adhesion. Materials Science and Engineering A, 1998. 245: p. 201-211.

2. Schulz, U., et al., Improvement of EB-PVD thermal barrier coatings by treatments of a vacuum plasma-sprayed bond coat. Surface and Coatings Technology, 2008. 203: p. 160-170.

3. Schulz, U., et al., Influence of substrate material on oxidation behavior and cyclic lifetime of EB-PVD TBC systems. Surface and Coatings Technology, 2001. 146-147: p. 117-123.

4. Saint-Ramond, B., et al., Low Mass Bondcoat for Robust Thermal Barrier Coatings. Materials Science Forum, 2004. 461-464: p. 265-272.

5. Brickey, M.R. and J.L. Lee, Structural and Chemical Analyses of a Thermally Grown Oxide Scale in Thermal Barrier Coatings Containing a Platinum-Nickel-Aluminide Bondcoat. Oxidation of Metals, 2000. 54(3-4): p. 237-254.

6. Angenete, J. and K. Stiller, Oxidation of Simple and Pt-Modified Aluminide Diffusion Coatings on Ni-Base Superalloys - II. Oxide Scale Failure. Oxidation of Metals, 2003. 60(1-2): p. 83-101.

7. Kestler, H. and H. Clemens, Titanium and Titanium alloys2002: Wiley-VCH Verlag, Weinheim.

8. Clemens, H., et al. in Ti 2003 Science and Technology. 2003. Hamburg, Germany: Wiley-VCH Verlag, Weinheim.

9. Clemens, H. and S. Meyer, Design, Processing, Microstructure, Properties, and Applications of Advanced Intermetallic TiAl Alloys. Advanced Engineering Materials, 2013. 15(4): p. 191-215.

10. Smarsly, W., et al. Titanium Aluminides for Automotive and Gas Turbine Applications. in Structural Intermetallics. 2001. Wyoming.

11. Brady, M.P., et al., The Oxidation and Protection of Gamma Titanium Aluminides. Journal of The Minerals, Metals \& Materials Society 1996. 48(11): p. 46-50.

12. Schmitz-Niederau, M. and M. Schütze, The Oxidation Behavior of Several Ti-Al Alloys at $900^{\circ} \mathrm{C}$ in Air. Oxidation of Metals, 1999. 48(3-4): p. 225-240. 
13. Donchev, A., R. Braun, and M. Schütze, Optimizing Thermally Grown Oxide for Thermal Barrier Coatings on TiAl Components via Florine Treatment. Journal of The Minerals, Metals \& Materials Society, 2010. 62(1): p. 70-74.

14. Donchev, A., B. Gleeson, and M. Schütze, Thermodynamic considerations of the beneficial effect of halogens on the oxidation resistance of TiAl-based alloys. Intermetallics, 2003. 11: p. 387-398.

15. Friedle, S., et al., Thermal barrier coatings on $\gamma$-TiAl protected by the halogen effect. Surface and Coatings Technology, 2012. 212: p. 72-78.

16. Pflumm, R., S. Friedle, and M. Schütze, Oxidation protection of g-TiAl-based alloys A review. Intermetallics, 2015. 56: p. 1-14.

17. Zhou, C., et al., Effect of Ti-Al-Cr coatings on the high temperature oxidation behavior of TiAl alloys. Materials Science and Engineering A, 2001. 307: p. 182-187.

18. Fröhlich, M., R. Braun, and C. Leyens, Oxidation resistant coatings in combination with thermal barrier coatings on $\gamma$-TiAl alloys for high temperature applications. Surface and Coatings Technology, 2006. 201: p. 3911-3917.

19. Gauthier, V., et al., Oxidation-Resistant Aluminide Coatings on $\gamma$-TiAl. Oxidation of Metals, 2003. 59(3-4): p. 233-255.

20. Liu, Z. and G. Wang, Improvement of oxidation resistance of $\gamma$-TiAl At 800 and $900 \mathrm{C}$ in air by TiAl2 coatings. Materials Science and Engineering A, 2005. 397(1-2): p. 5057.

21. Laska, N., R. Braun, and S. Knittel, Oxidation behavior of protective Ti-Al-Cr based coatings applied on the $\gamma$-TiAl alloys Ti-48-2-2 and TNM-B1. Surface and Coatings Technology, 2018. 349: p. 347-356.

22. Ebach-Stahl, A., et al., Improvement of the High-Temperature Oxidation Resistance of $\gamma$-TiAl by Selectively Pre-treated Si-based Coatings. Advanced Engineering Materials, 2008. 10(7): p. 675-677.

23. Xiong, H.-P., et al., Formation of silicide coatings on the surface of a TiAl-based alloy and improvement in oxidation resistance. Materials Science and Engineering A, 2005. 391: p. 10-18.

24. Li, X.Y., et al., Influence of siliconizing on the oxidation behavior of a $\gamma$-TiAl based alloy. Intermetallics, 2003. 11(2). 
25. Ebach-Stahl, A. and M. Fröhlich, Oxidation study of Pt-Al based coatings on $\gamma$-TiAl at $950^{\circ} \mathrm{C}$. Surface and Coatings Technology, 2016. 287: p. 20-24.

26. Das, D.K. and Z. Alam, Cyclic oxidation behaviour of aluminide coatings on Ti-base alloy IMI-834 at $750^{\circ} \mathrm{C}$. Surface and Coatings Technology, 2006. 201: p. 3406-3414.

27. Das, D.K. and S.P. Trivedi, Microstructure of diffusion aluminide coatings on Ti-base alloy IMI-834 and their cyclic oxidation behaviour at $650 \circ \mathrm{C}$. Materials Science and Engineering A, 2004. 367(1-2): p. 225-233.

28. Gurrappa, I. and A.K. Gogia, High performance coatings for titanium alloys to protect against oxidation. Surface and Coatings Technology, 2001. 139: p. 216-221.

29. Gauthier, V., F. Dettenwanger, and M. Schütze, Oxidation behavior of $\gamma$-TiAl coated with zirconia thermal barriers. Intermetallics, 2002. 10(7): p. 667-674.

30. Leyens, C., et al. Enviromental Protection of Gamma Titanium Aluminides. in TMS. 2003. San Diego: The Minerals, Metals \& Materials Society.

31. Leyens, C., et al., Recent Progress in the coating Protection of Gamma TitaniumAluminides. Journal of Metals, 2006. 92: p. 17-21.

32. Beele, W., G. Marijnissen, and A. van Lieshout, The evolution of thermal barrier coatings - status and upcoming solutions for today's key issues. Surface and Coatings Technology, 1999. 120-121: p. 61-67.

33. Padture, N.P., M. Gell, and E.H. Jordan, Thermal Barrier Coatings for Gas-Turbine Engine Applications. Science, 2002. 296: p. 280-284.

34. Laska, N. and R. Braun, Lifetime of Thermal Barrier Coatings Deposited on $\gamma$-TiAl Based Alloys Using Intermetallic Ti-Al-Cr Bond Coats with Additions of Yttrium and Zirconium. Oxidation of Metals, 2014. 81(1-2): p. 83-93.

35. Raghavan, V., Al-Pt-Ti (Aluminum-Platinum-Titanium). Journal of Phase Equilibria and Diffusion, 2010. 31(1): p. 59.

36. Ding, J.J., et al., Structural chemistry and phase relations in intermetallic systems $T i \pm\{P d, P t\} \pm A l$. Intermetallics, 2000. 8(12): p. 1377-1384.

37. Laska, N., et al., Lifetime of 7YSZ thermal barrier coatings deposited on fluorinetreated g-TiAl-based TNM-B1 alloy. Materials and Corrosion, 2016. 67(11): p. 11851194. 
38. Braun, R., et al., Oxidation behaviour of gamma titanium aluminides with EB-PVD thermal barrier coatings exposed to air at $900^{\circ} \mathrm{C}$. Surface and Coatings Technology, 2007. 202: p. 676-680.

39. Braun, R., et al., Thermally grown oxide scale on $\gamma$-TiAl coated with thermal protection systems. Materials at High Temperatures, 2009. 26(3): p. 305-316 
Table I: Compositions of Ti-Pt-Al phases at $900^{\circ} \mathrm{C}$; measured via EDS

\begin{tabular}{cccccc}
\hline $\begin{array}{c}\text { number of } \\
\text { cycles }\end{array}$ & phase & \multicolumn{4}{c}{ concentration c [at.\%] } \\
\hline \hline 10 & & $\mathrm{Al}$ & $\mathrm{Ti}$ & $\mathrm{Nb}$ & $\mathrm{Pt}$ \\
\hline \multirow{3}{*}{100} & $\mathrm{PtAl}$ & 44 & 4 & - & 52 \\
& $\mathrm{TiPt}_{2} \mathrm{Al}$ & 25 & 26 & - & 49 \\
& $\tau_{4}-(\mathrm{Ti}, \mathrm{Nb}) \mathrm{PtAl}$ & 29 & 31 & 6 & 34 \\
& $\mathrm{PtAl}$ & 54 & 0,5 & 5 & 40,5 \\
1500 & $\mathrm{Pt}_{2} \mathrm{Al}{ }_{3}$ & 54 & 11 & 3 & 32 \\
& $\tau_{4}-(\mathrm{Ti}, \mathrm{Nb}) \mathrm{PtAl}$ & 31 & 29 & 7 & 33 \\
& $\tau_{4}-(\mathrm{Ti}, \mathrm{Nb}) \mathrm{PtAl}$ & 32 & 33 & 1 & 34 \\
& $\tau_{2}-(\mathrm{Ti}, \mathrm{Nb}) \mathrm{PtAl}_{2}$ & 45 & 29 & 2 & 24 \\
& $\tau_{4}-(\mathrm{Ti}, \mathrm{Nb}) \mathrm{PtAl}$ & 31 & 34 & 1 & 34 \\
& $\tau_{2} / \tau_{3}$ & 39 & 28 & 8 & 25 \\
& $\tau_{2}-(\mathrm{Ti}, \mathrm{Nb}) \mathrm{PtAl}_{2}$ & 42 & 34 & 2 & 22 \\
\hline
\end{tabular}


Table II: Compositions of Ti-Pt-Al phases at $1000^{\circ} \mathrm{C}$; measured via EDS

\begin{tabular}{|c|c|c|c|c|c|c|}
\hline \multirow{2}{*}{$\begin{array}{c}\text { temperature } \\
1000^{\circ} \mathrm{C} \\
\end{array}$} & \multirow{2}{*}{$\begin{array}{c}\text { number of } \\
\text { cycles }\end{array}$} & \multirow[t]{2}{*}{ phase } & \multicolumn{4}{|c|}{ concentration c [at.\%] } \\
\hline & & & $\mathrm{Al}$ & $\mathrm{Ti}$ & $\mathrm{Nb}$ & $\mathrm{Pt}$ \\
\hline \multirow[t]{9}{*}{ without TBC } & 10 & $\mathrm{Pt}_{2} \mathrm{Al}_{3}$ & 55 & 11 & 3 & 31 \\
\hline & & PtAl & 54,5 & 1,5 & 3 & 41 \\
\hline & & $\tau_{3}$ & 36 & 29 & 10 & 25 \\
\hline & & $\tau_{4}-(\mathrm{Ti}, \mathrm{Nb}) \mathrm{PtAl}$ & 30 & 31 & 5 & 34 \\
\hline & 100 & $\mathrm{Pt}_{2} \mathrm{Al}_{3}$ & 54,5 & 14 & 1,5 & 30 \\
\hline & & $\tau_{2}-(\mathrm{Ti}, \mathrm{Nb}) \mathrm{PtAl}_{2}$ & 50 & 20 & 2,5 & 28,5 \\
\hline & & $\tau_{3}$ & 38 & 32 & 8 & 22 \\
\hline & 1500 & $\tau_{2}-(\mathrm{Ti}, \mathrm{Nb}) \mathrm{PtAl}_{2}$ & 46 & 16 & 9 & 29 \\
\hline & & $\tau_{3}$ & 43 & 30 & 2 & 25 \\
\hline \multirow[t]{5}{*}{ with TBC } & as coated & PtAl & 54 & 2 & 2 & 42 \\
\hline & & $\mathrm{Pt}_{2} \mathrm{Al}_{3}$ & 52 & 13 & 2 & 33 \\
\hline & & $\tau_{4}-(\mathrm{Ti}, \mathrm{Nb}) \mathrm{PtAl}$ & 29 & 33 & 5 & 34 \\
\hline & 1500 & $\tau_{4}-(\mathrm{Ti}, \mathrm{Nb}) \mathrm{PtAl}$ & 31 & 31 & 3 & 35 \\
\hline & & Nb-rich TiAl & 29 & 42 & 21 & 8 \\
\hline
\end{tabular}




\section{Figure captions}

Figure 1: Mass changes of Pt-53Al coating on $\gamma$-TiAl at $900^{\circ} \mathrm{C}$

Figure 2: XRD-diffractogram of $\mathrm{PtAl}$ coating after different cycles at $900^{\circ} \mathrm{C}$

Figure 3: Ternary phase diagram Ti-Pt-Al leaned on [35] including measured EDS-data

Figure 4: SEM micrograph of Pt-53Al coating tested at $900^{\circ} \mathrm{C}$
a) 10 cycles
b) 100 cycles
c) 1500 cycles

Figure 5: SEM micrograph of Pt-53Al coating tested at $1000^{\circ} \mathrm{C}$
a) 10 cycles
b) 1500 cycles
c) Formation of blistering after 1000 cycles

Figure 6: XRD-diffractogram of PtAl coating after different cycles at $1000^{\circ} \mathrm{C}$

Figure 7: SEM micrograph of Pt-53Al $+\mathrm{TBC}$ coating tested at $1000^{\circ} \mathrm{C}$
a) After $\mathrm{TBC}$ deposition
b) 1500 cycles 


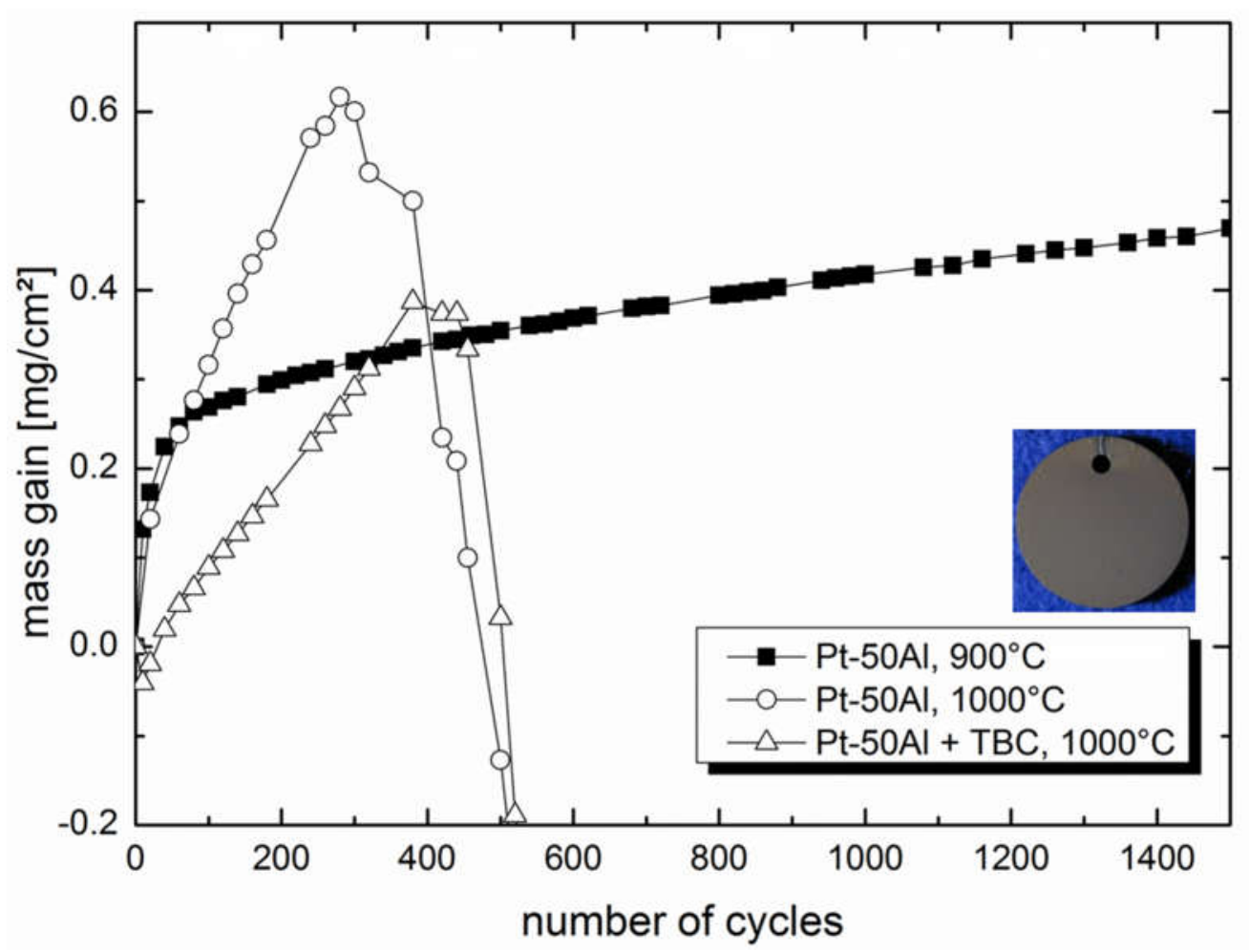

Figure 1



Figure 2 


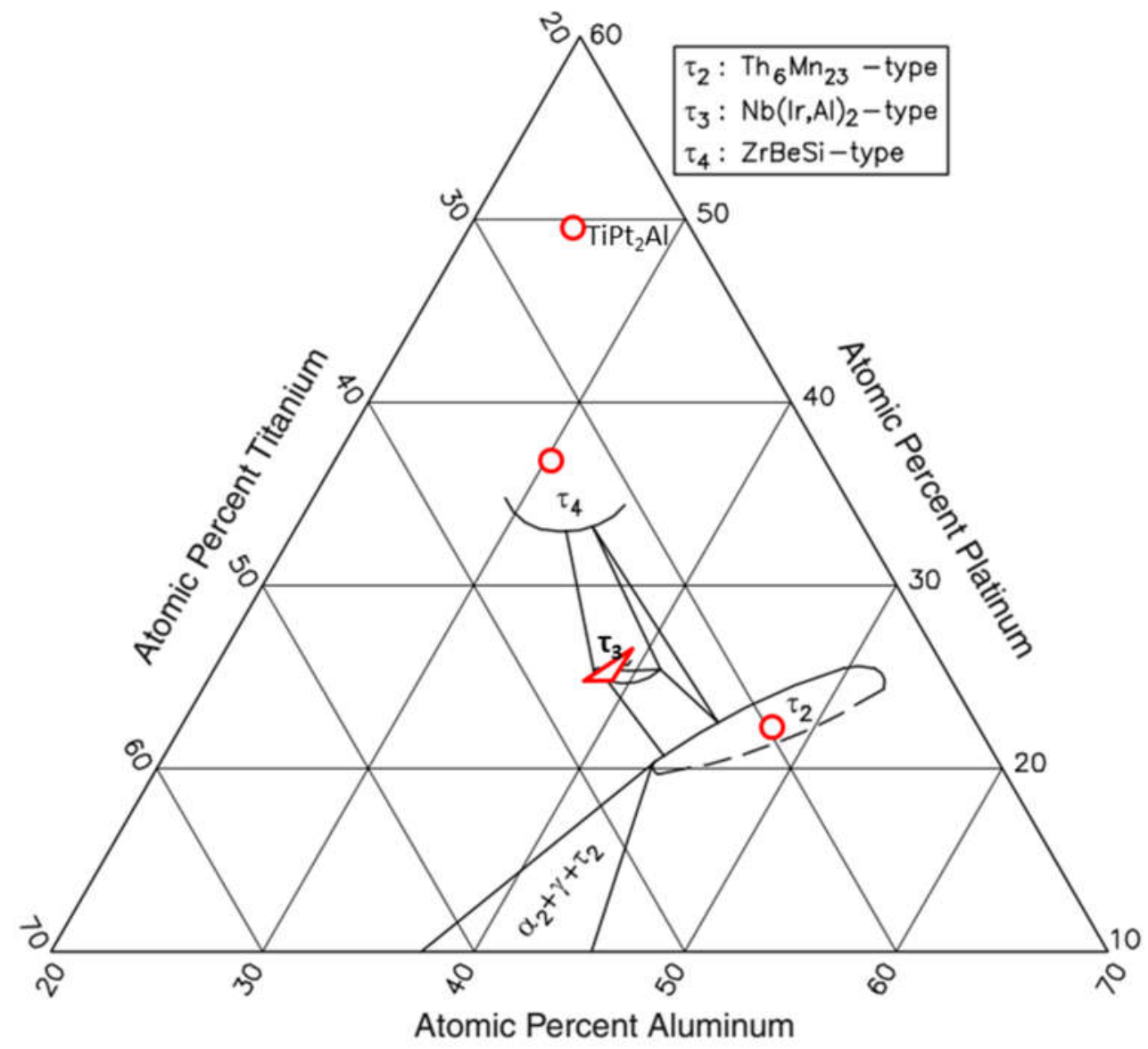

Figure 3



Figure 4a 


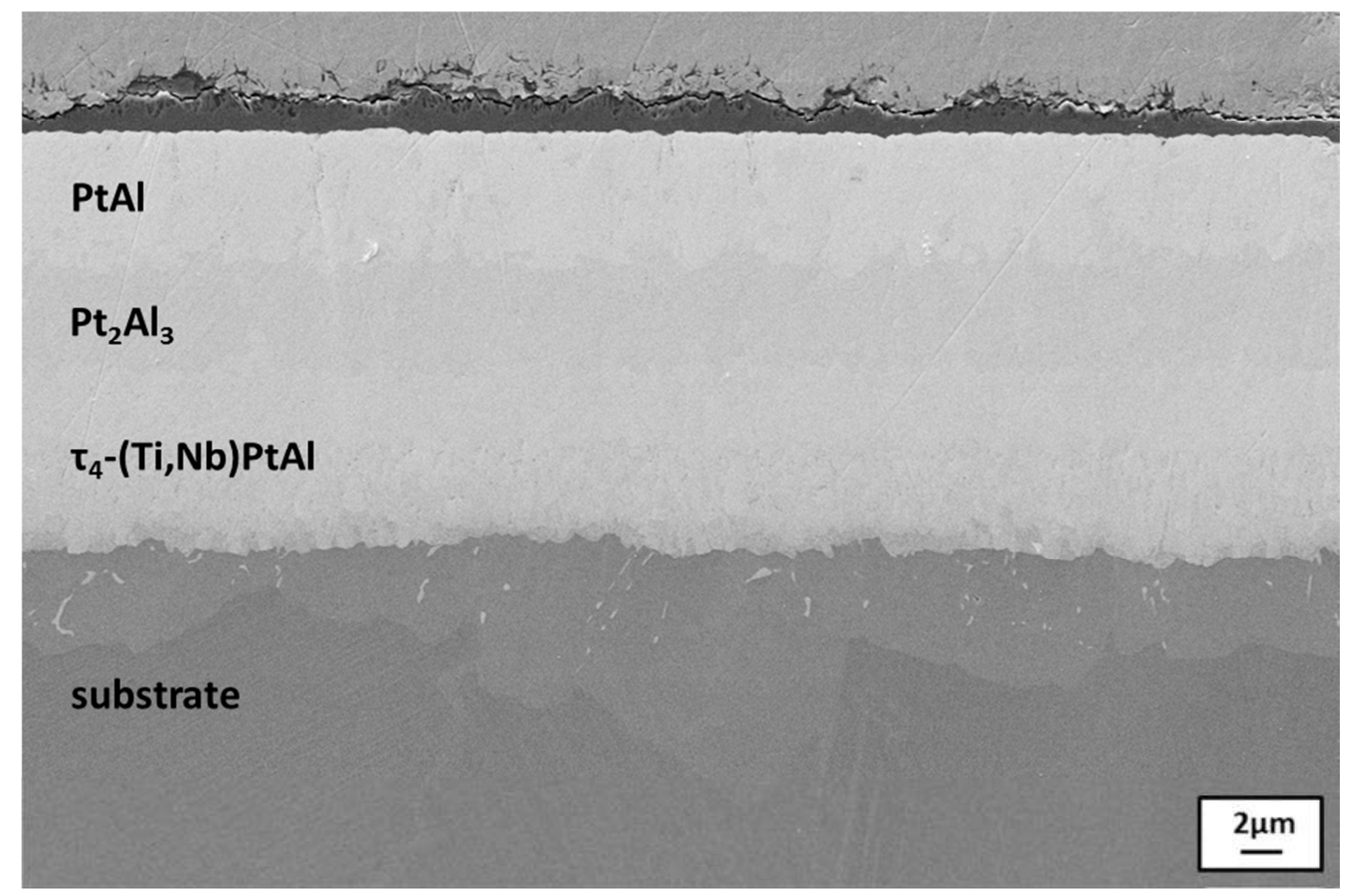

Figure $4 b$

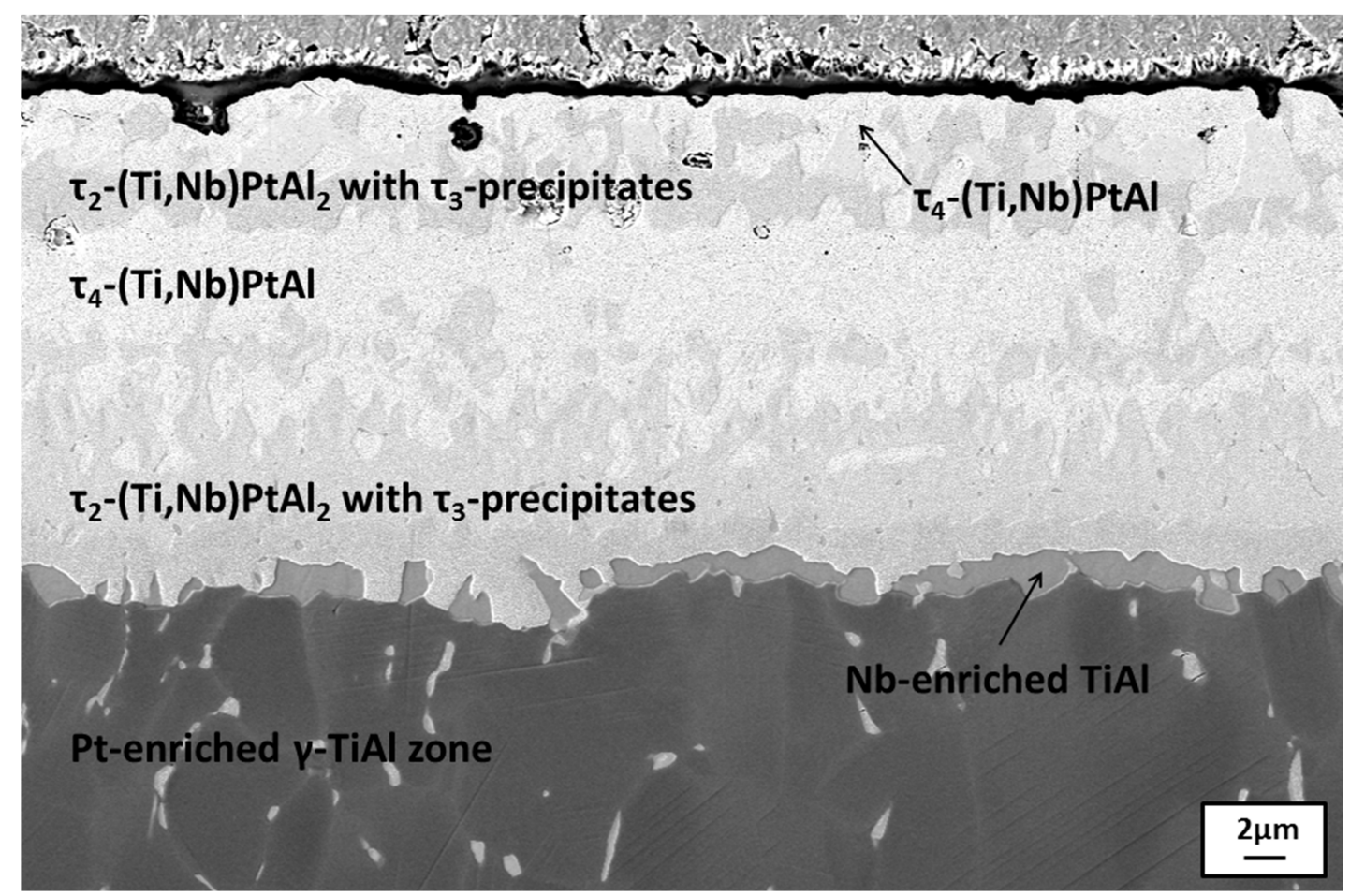

Figure 4c 




Figure 5a

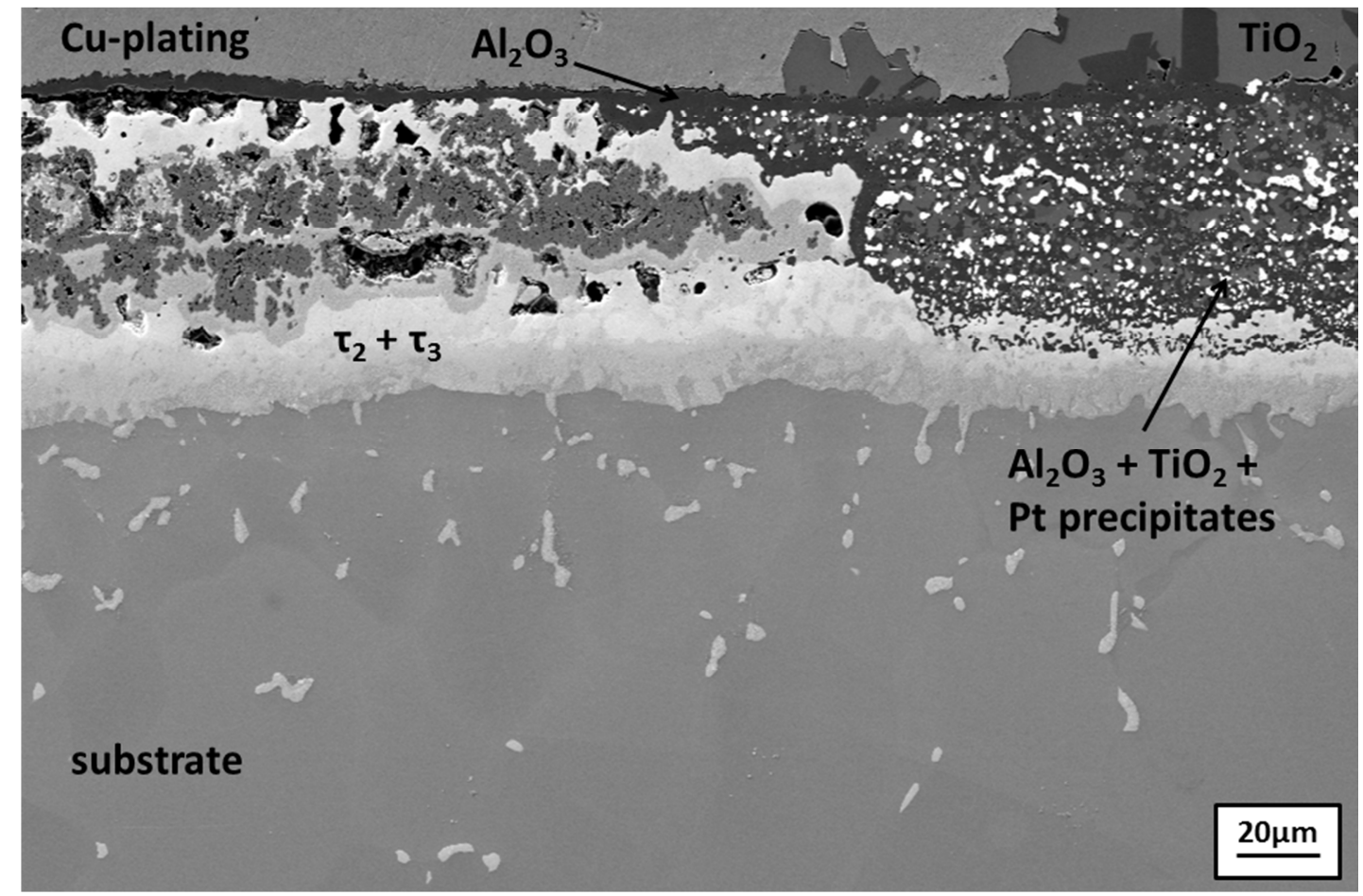

Figure $5 b$ 


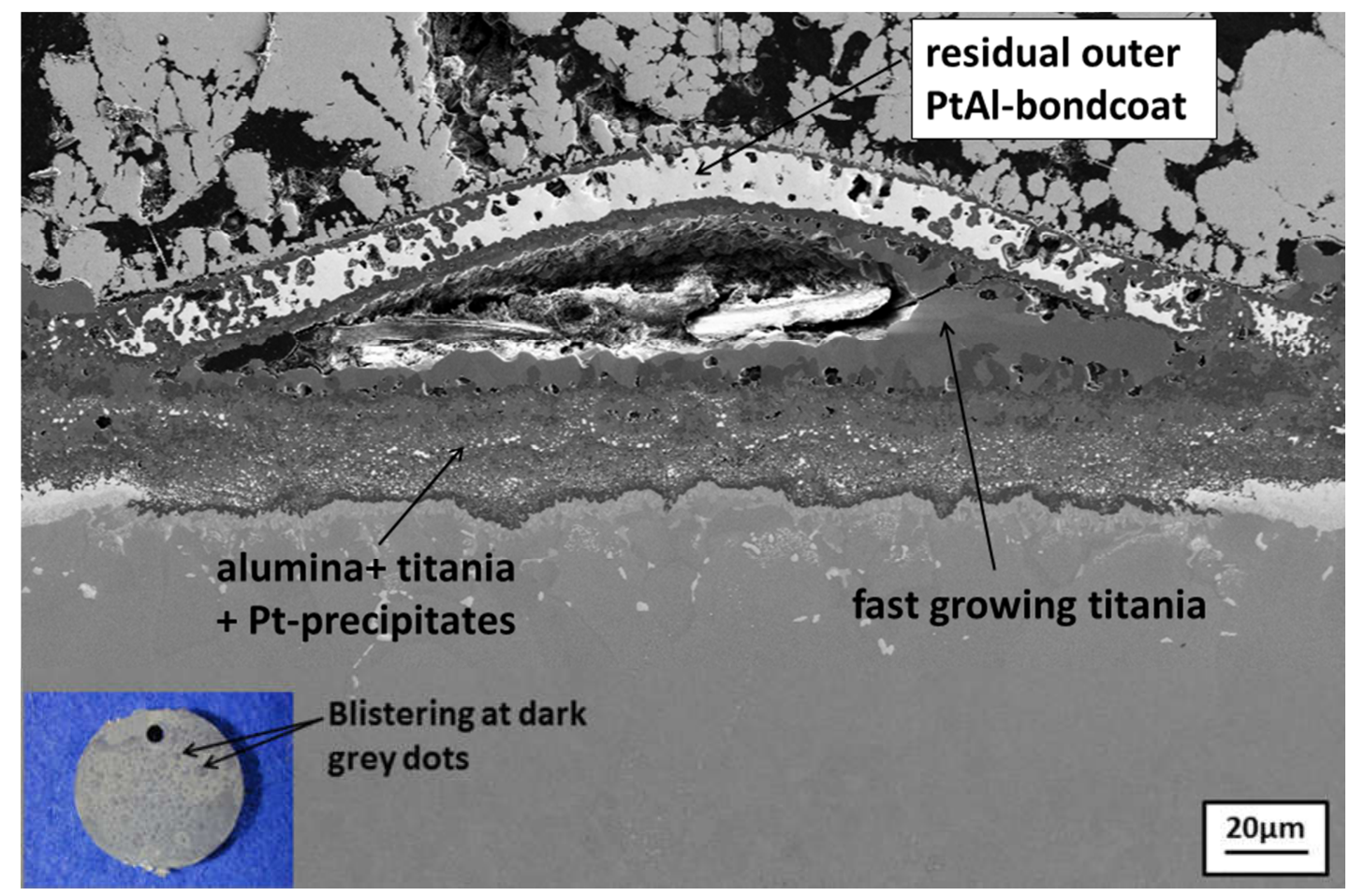

Figure 5c

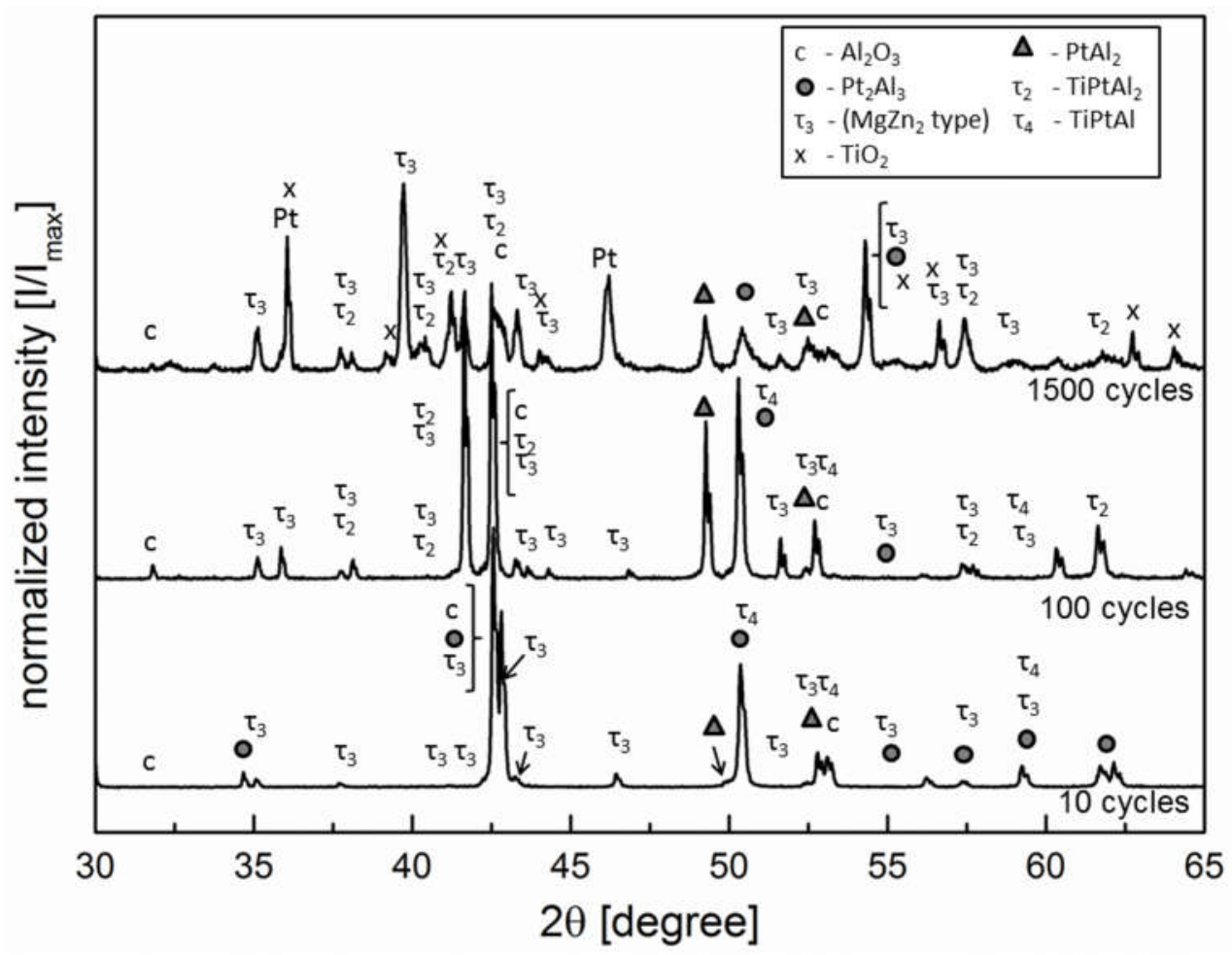

Figure 6 


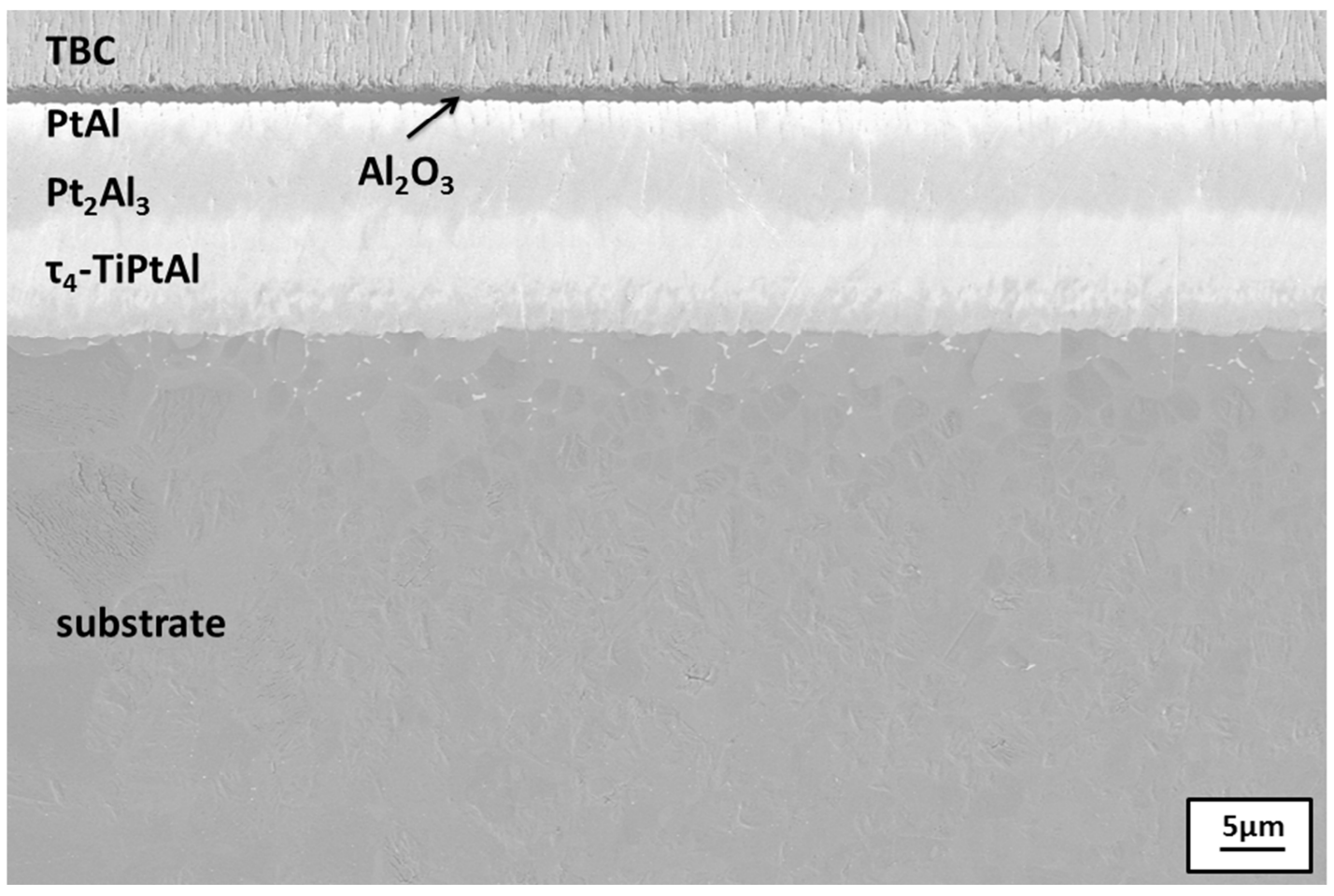

Figure 7a

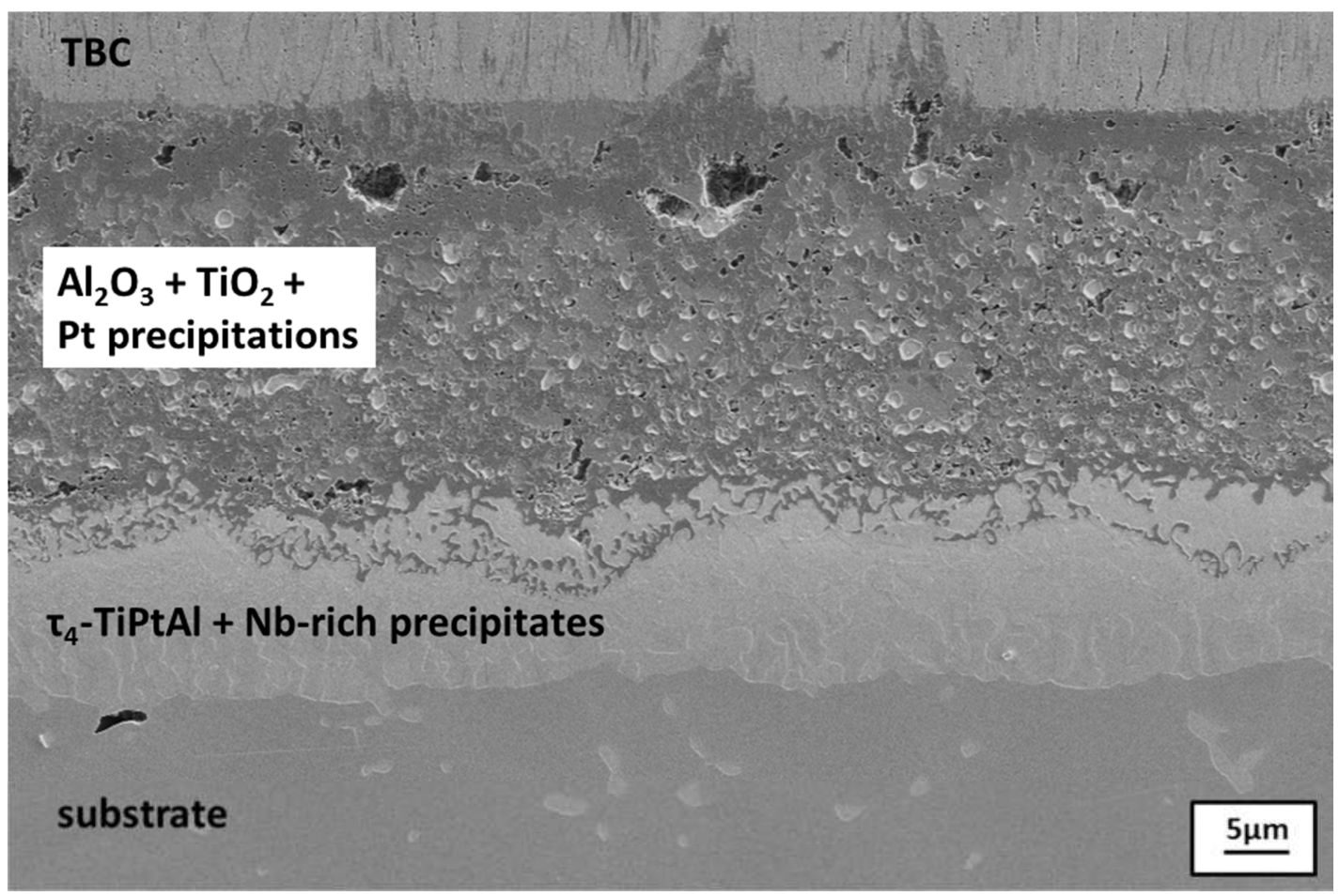

Figure $7 b$ 